\title{
Philippe AUdEGEAN, La Philosophie de Beccaria. Savoir
} punir, savoir écrire, savoir produire

\section{Sébastien Annen}

\section{(2) OpenEdition \\ Journals}

Édition électronique

URL : https://journals.openedition.org/ahrf/12351

DOI : 10.4000/ahrf.12351

ISSN : 1952-403X

Éditeur :

Armand Colin, Société des études robespierristes

Édition imprimée

Date de publication : 1 juin 2012

Pagination : 198-199

ISBN : 978-2-7489-0161-0

ISSN : 0003-4436

\section{Référence électronique}

Sébastien Annen, «Philippe audegean, La Philosophie de Beccaria. Savoir punir, savoir écrire, savoir produire ", Annales historiques de la Révolution française [En ligne], 368 | avril-juin 2012, mis en ligne le 24 septembre 2012, consulté le 23 avril 2022. URL : http://journals.openedition.org/ahrf/12351 ; DOI : https://doi.org/10.4000/ahrf.12351

Ce document a été généré automatiquement le 23 avril 2022.

Tous droits réservés 


\title{
Philippe AUdEGEAN, La Philosophie de Beccaria. Savoir punir, savoir écrire, savoir produire
}

\author{
Sébastien Annen
}

\section{RÉFÉRENCE}

Philippe AUDEGEAN, La Philosophie de Beccaria. Savoir punir, savoir écrire, savoir produire, Paris, Vrin, 2010, 285 p., ISBN 978-2-7116-2303-7, $23 €$.

1 Ce travail est l'utile complément de la nouvelle édition critique des Délits et des peines / Dei delitti e delle pene (ENS Éditions, 2009, cf. compte rendu dans AHRF, 360, avriljuin 2010). Surtout, ce livre est issu d'une thèse de philosophie préparée sous la direction de Jean-Fabien Spitz et soutenue en 2003 à l'université de Paris 1. La Philosophie de Beccaria interroge la cohérence des œuvres du Milanais en soulevant dès l'introduction le "problème Beccaria ». Si tout le monde connaît Des délits et des peines (1764) et si l'on peut comprendre la rédaction des Éléments d'économie publique (1769-1770) dans la mesure où Beccaria est nommé professeur d'économie en 1768, que viennent donc faire dans ce parcours intellectuel les Recherches concernant la nature $d u$ style (1770)?

2 Philippe Audegean parie sur la cohérence d'ensemble en insistant plutôt sur la méthode et l'ambition à la fois théorique et pratique du Milanais. Sa philosophie est d'abord une méthode critique des savoirs constitués : le droit pénal, la rhétorique et l'économie deviennent alors trois continents épistémologiques que Beccaria entend refonder. La philosophie s'impose comme l'instrument des réformes à accomplir pour savoir punir, savoir écrire et savoir produire dans la société qu'il s'agit de faire advenir en ce second $\mathrm{xvIII}{ }^{\mathrm{e}}$ siècle.

3 Le premier chapitre commence par présenter la conception beccarienne du contrat social qui emprunte une voie originale entre Hobbes et Rousseau. Si les hommes ont 
formé société, ce n'est pas pour répondre à une menace de mort imminente ni par amour de la raison ou de l'intérêt général mais par lassitude, pour protéger leurs intérêts privés, pour être certains de jouir enfin de leur liberté en toute tranquillité et pour pouvoir envisager sereinement un futur prévisible. La société selon Beccaria est donc fondée sur la nécessité et l'utilité. Il estime dès lors que savoir punir, savoir écrire et savoir produire, c'est savoir penser et agir seulement quand cela s'avère utile et nécessaire, dans le but d'octroyer le plus de bonheur possible au plus grand nombre, sans jamais retomber dans l'incertitude, la tyrannie ou la superstition.

méthode de Beccaria consiste alors à s'emparer d'un savoir constitué qu'il estime dépassé et inefficace : la vieille législation fondée sur l'arbitraire et sur la terreur, la vieille rhétorique fondée sur un prétendu génie littéraire et enfin la vieille économie fondée sur la lutte des intérêts et sur l'intrusion de l'État. Chaque savoir est ensuite appréhendé comme une équation mathématique qui, une fois simplifiée, permet d'en isoler le principe fondamental capable à lui seul de réorganiser ce savoir en garantissant toujours la liberté civile, c'est-à-dire en permettant aux intérêts particuliers de se déployer le plus possible en toute tranquillité.

Savoir punir, c'est infliger les moindres maux possibles en vertu du "principe de parcimonie punitive» (p. 147). Pour être efficaces et légitimes, les lois doivent être minimales, précises et universelles. Elles n'ont pas à être interprétées mais strictement appliquées par le juge automate - sans quoi la législation se trouverait à nouveau soumise au règne de l'arbitraire et de l'incertitude. La théorie de l'histoire de Beccaria le conduit à défendre un pouvoir qui soit le plus en retrait possible de la vie des citoyens : ni despotique (le vice ne devant pas être encouragé) ni vertueux (la vertu étant un idéal non raisonnable), le pouvoir et la législation doivent être modérés et doux. Savoir écrire revient à être capable de communiquer des idées en provoquant le plus de sensations sans verser dans l'ennui ni la saturation. C'est s'exprimer de manière efficace et esthétique - étant entendu que l'utile et le beau s'épaulent pour cultiver les sentiments et la raison des hommes afin de contribuer au progrès social. Enfin, savoir produire, c'est parvenir à créer la plus grande quantité possible de travail utile en développant une "technique de bien-être général »(p.224). De la même façon que Beccaria refuse l'interventionnisme législatif, il estime que le commerce sera plus développé et les intérêts plus prompts à s'entendre pourvu que le pouvoir renonce à l'interventionnisme économique. Toujours utilitariste, Beccaria s'impose donc comme l'un des penseurs majeurs du libéralisme. Chacune des règles fondamentales, qui organisent les savoirs qu'il refonde, se justifie à la fois par le raisonnement et par l'empirisme, par les principes et par les faits. Philippe Audegean peut ainsi replacer Beccaria dans le courant des Lumières italiennes réformatrices et engagées dans la vie publique - à l'inverse des Lumières françaises perçues comme révolutionnaires parce qu'idéalistes et peu impliquées dans les affaires publiques.

6 En décortiquant et en réorganisant raisonnablement ces savoirs anciens pour les régénérer, Beccaria entend les rendre appréhendables, compréhensibles, évidents et légitimes. Il les place au centre de l'espace public à disposition de chacun. Surtout, il les sort de l'emprise exercée par les aristocrates du savoir, ceux qui se prétendent les uniques interprètes de cette langue soi-disant sacrée du droit et de la rhétorique. Au fond, par sa méthode philosophique, Beccaria réinvente le feu pour le redonner aux hommes en permettant à chacun de s'emparer du savoir sans dépendre de l'interprétation d'autrui. Il veut affranchir les citoyens de la déférence et les rendre 
capables de résister aux tyrannies. S'inscrivant dans les pas de Michel Foucault et de Roger Chartier, Philippe Audegean peut ainsi déclarer que «la philosophie permet de soustraire le jugement politique et l'appréciation esthétique aux institutions autorisées et de les livrer au tribunal de l'opinion publique » (p. 254).

7 La problématique de l'ouvrage permet de s'affranchir, une fois n'est pas coutume, du magistère exercé par Des délits et des peines - bien que trois chapitres sur cinq soient encore consacrés à cet ouvrage, au prix de quelques répétitions. On regrette que les nouvelles thématiques du style et de l'économie n'aient droit qu'à un chapitre chacune alors qu'elles auraient certainement mérité des développements plus approfondis. On aurait aimé en apprendre plus sur les techniques efficaces de communication ainsi que sur le rôle du beau style dans le progrès social. Quant à certains passages qui semblent faire de Beccaria l'inventeur d'un savoir économique inédit, ils n'interrogent pas suffisamment la genèse de l'économie politique et les rapports entre le libéralisme de Beccaria et le caméralisme en vogue au XVIII ${ }^{\mathrm{e}}$ siècle. Malgré un style parfois inutilement complexe, la thèse de l'ouvrage est véritablement stimulante. En retrouvant le fil rouge méthodologique qui unit les écrits de Cesare Beccaria sur le droit, le style et l'économie, Philippe Audegean éclaire d'un jour nouveau la logique réformatrice de celui qu'il n'est désormais plus possible de réduire à la seule question des réformes judiciaires au siècle des Lumières. 